\title{
Fir Cercariae developing in Lymnaea natalensis Krauss, 1848 collected in the vicinity of Pretoria, Gauteng Province, South Africa
}

\author{
E.B.E. MOEMA ${ }^{1}$, P.H. KING ${ }^{1 *}$ and C. BAKER ${ }^{2}$
}

\begin{abstract}
MOEMA, E.B.E, KING, P.H. \& BAKER, C. 2008. Cercariae developing in Lymnaea natalensis Krauss, 1848 collected in the vicinity of Pretoria, Gauteng Province, South Africa. Onderstepoort Journal of Veterinary Research, 75:215-223

Freshwater snails are known to serve as first intermediate hosts for various parasitic diseases such as schistosomosis and fasciolosis. Snails were collected on several occasions in the proximity of Pretoria, South Africa and their cercarial sheddings were studied. This article describes three different types of cercariae shed by the freshwater snail, Lymnaea natalensis, viz. a fork-tailed cercaria of a Trichobilharzia sp., an avian parasite belonging to the family Schistosomatidae, an echinostomatid cercaria of the family Echinostomatidae, also avian parasites and a xiphidiocercaria of the family Plagiorchiidae which parasitise avians and amphibians. The morphology of these cercariae was studied by light and scanning electron microscopy.
\end{abstract}

Keywords: Cercariae, Lymnaea natalensis, parasites, Schistosoma, snails, Trichobilharzia, sp.

\section{INTRODUCTION}

Molluscs, usually snails, serve as first intermediate hosts for a large number of trematode parasites, e.g. Schistosoma spp. in humans and animals (Appleton 1996). Brown (1994) mentioned that approximately 400 species of freshwater snails (including limpets) occur in Africa, some of which form an important part of freshwater ecosystems for inland fisheries where they provide a valuable source of food.

Lymnaeid snails are the first intermediate hosts for several Fasciola spp. The main snail host for the

* Author to whom correspondence is to be directed: E-mail: pking@ul.ac.za

1 Department of Biology, University of Limpopo, Medunsa Campus, P.O. Box 139, Medunsa, 0204 South Africa

2 Electron Microscope Unit, University of Limpopo, Medunsa Campus, P.O. Box 84, Medunsa, 0204 South Africa

Accepted for publication 21 May 2008-Editor liver fluke, Fasciola gigantica, is Lymnaea natalensis which is widely distributed in Africa (Brown 1994). Another study by Van Eeden, Brown \& Oberholzer (1965) indicated that this species also has a wide distribution range in South Africa that extends into the Western Cape (as far as the Knysna district), Kwa-Zulu Natal and the eastern Mpumalanga provinces. Surveys executed over the past 2 years in farm dams and other waterbodies around Pretoria showed $L$. natalensis to be the most abundant freshwater snail in this area.

The aim of this study was to examine different cercariae shed by $L$. natalensis in dams surrounding Pretoria, Gauteng Province, as well as to gather information on other life stages within the life cycles of these parasites.

\section{MATERIALS AND METHODS}

Lymnaea natalensis specimens were collected over a period of 2 years using metal scoops as described 
by Van Eeden (1960). Snails found under water lilly leaves were also collected manually. In the laboratory they were kept in plastic containers and fed fish flakes. They were exposed individually to daylight (but not direct sunlight) to stimulate the natural shedding of cercariae. The cercariae were stained with nile blue sulphate or neutral red vital stains and studied by light microscopy while alive. Drawings were made with a drawing tube and measurements were derived from these drawings. In all cases 20 specimens were measured and all measurements given in the descriptions are in micrometres $(\mu \mathrm{m})$. Minimum and maximum values are indicated with the mean value and standard deviation in brackets. No other intra-molluscan stages were collected.

For scanning electron microscopy (SEM), specimens were fixed overnight in $2.5 \%$ glutaraldehyde, washed in Millonig's phosphate buffer $(\mathrm{pH}=7.2)$ and dehydrated through a graded ethanol series for $30 \mathrm{~s}$ to $1 \mathrm{~min}$ in each concentration. Thereafter, they were critical point dried (Polaron, UK) overnight, mounted on stubs, sputter coated with gold (Emscope, UK) and examined using a Leica Stereoscan 420 scanning electron microscope (Leica Electron Optics, UK) at the Electron Microscope Unit of the University of Limpopo (Medunsa Campus).

In a preliminary life cycle study, two Mallard ducks and two Wisstar rats were exposed to the fork-tailed cercariae. A small number of cercariae were placed with the experimental animals and left for $1 \mathrm{~h}$. Dissection of the animals took place 3 weeks later.

\section{RESULTS}

Three types of cercariae were identified, namely the fork-tailed type, and two single-tailed types, one of which is an echinostome and the other a xiphidiocercaria.

\section{Fork-tailed cercaria (Fig. 1A-B and 2A-H)}

The cercaria (Fig. 1A-B and 2A) comprises an oval body and long tail stem terminating in two furcal rami. The body measures $233-257(243 \pm 9)$ long $x$ 59-79 $(63 \pm 7)$ wide. The oral sucker is protrusible, measures 61-73 $(68 \pm 4) \times 40-46(44 \pm 1)$, and a few ciliated sensory receptors surround it (Fig. 2C). Prominent openings of the penetration gland ducts (Fig. 2D) are also visible by SEM. The oesophagus, $12-28(21 \pm 4) \times 2.9-4.5(3.7 \pm 1)$, bifurcates anteriorly to the acetabulum into two intestinal caeca, $12-21(15 \pm 2) \times 3-6(5 \pm 1)$, that end blindly at the mid-level of the first penetration glands. One of the most characteristic features of this cercaria is the

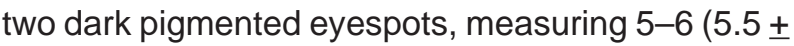
1) $\times 5-6(5.5 \pm 1)($ Fig. $2 B)$, that are situated in the mid-body bilateral to the blind-ending caeca.

The acetabulum (Fig. 2E), 13-18 (16 \pm 1$) \times 12-19$ $(16 \pm 2)$ is very protrusible and is situated 78-97 (86 $\pm 8)$ from the oral sucker and 67-92 $(73 \pm 8)$ from the posterior end of the body. Five pairs of penetration glands (Fig. $1 \mathrm{~A}$ ) were observed between the eyespots and excretory bladder. The first pair is coarsely granulated, situated anteriorly to the acetabulum and measures $43-45(44 \pm 1) \times 22-24(23 \pm 1)$. The remaining pairs are finely granulated and situated posteriorly to the acetabulum, measuring 19-25 (22 $\pm 4) \times 4-16(10 \pm 8)$. The penetration ducts extend anteriorly to the oral sucker where they open exteriorly (Fig. 1A).

The excretory bladder is $Y$-shaped measuring 6-13 $(9 \pm 3) \times 7-16(10 \pm 3)($ Fig. $1 \mathrm{~A})$. From the bladder an excretory duct extends posteriorly into the tail that terminates in an opening on the tip of each caudal ramus (Fig. $2 \mathrm{H}$ ). The main excretory duct on either side of the bladder extends anteriorly and divides opposite to the acetabulum to form anterior and posterior collecting ducts. Six pairs of flame cells were observed in the body, three occurring posteriorly and three anteriorly to the acetabulum. The flame cell formula is $2(3+3)=12$.

The body tegument displays many backwardly directed spines (Fig. 2F and $G$ ), which decrease in number towards the posterior end of the body. The tail stem (Fig. 1A) is narrower than the body and measures 341-371 $(353 \pm 13) \times 30-50(39 \pm 7)$. The furcal rami, measuring 178-199 $(154 \pm 7) \times 15-$ $36(25 \pm 7)($ Fig. $2 \mathrm{H})$, is shorter than the tail stem. Both the tail stem and furcal rami are covered by less and shorter backwardly directed spines (Fig. $2 \mathrm{G}$ and $\mathrm{H}$ ). No sensory receptors were observed on the tail tegument.

\section{Remarks}

The cercaria is classified as a brevifurcate-apharyngeate distome cercaria according to the taxonomic key of Frandsen \& Christensen (1984). It is placed in the family Schistosomatidae and is commonly known as an avian cercaria as the adult parasites are mostly found in ducks and geese (Appleton 1986). This cercaria with its characteristic schistosome morphology has one unique feature, i.e. a pair of dark pigmented eyespots, which differentiates it from human schistosome cercariae. 


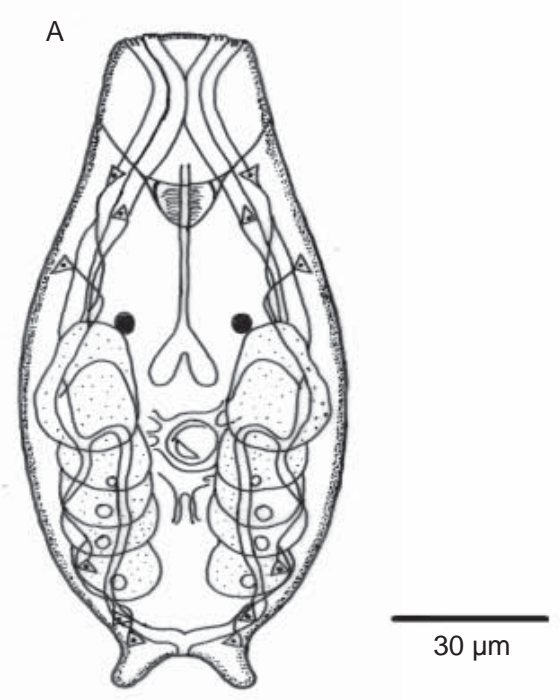

B
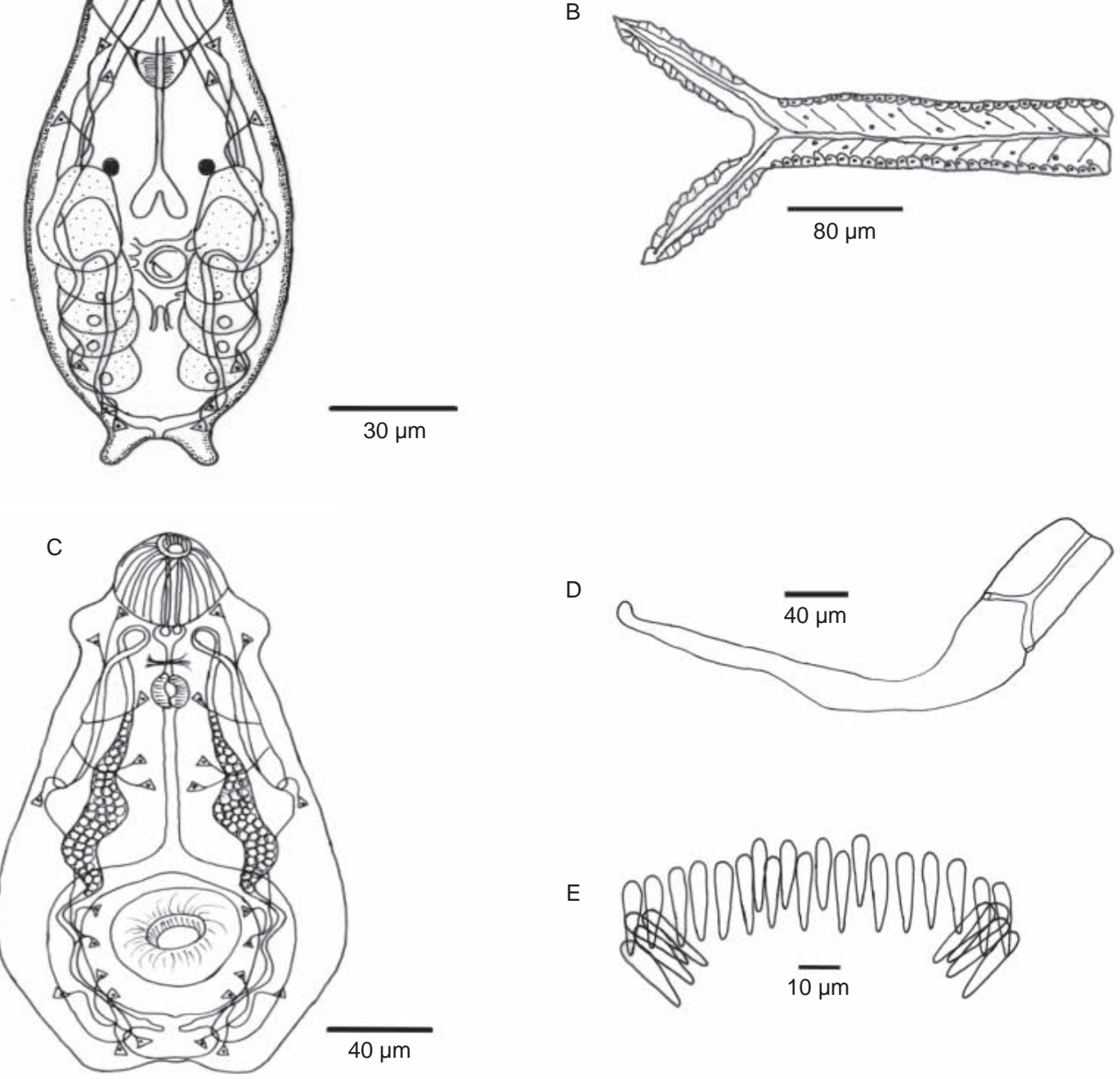

$\mathrm{E}$
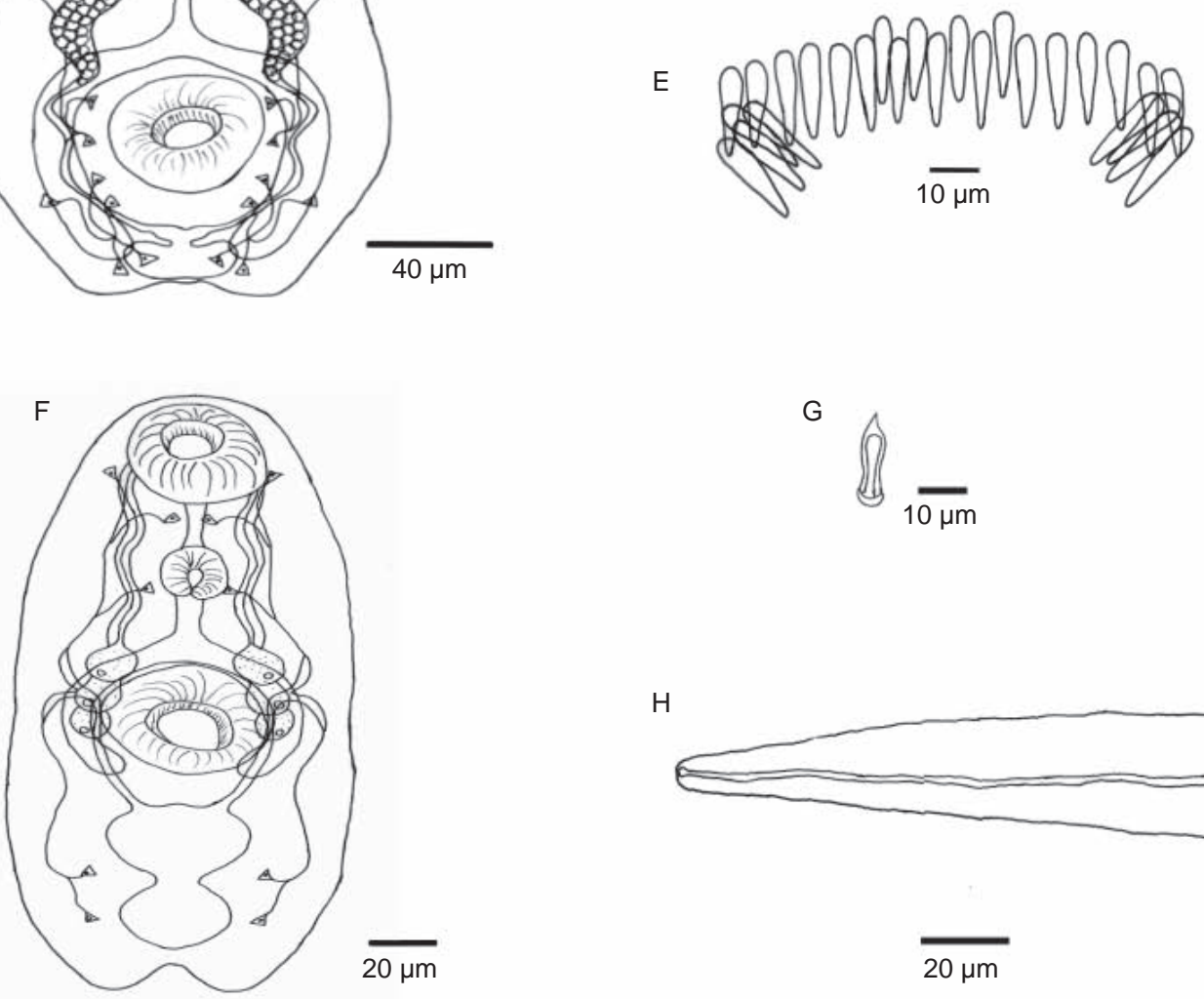

G

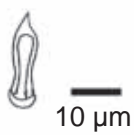

$\mathrm{H}$

$\overline{20 \mu \mathrm{m}}$

FIG. 1 Light microscope projection drawings of three types of cercariae shed by Lymnaea natalensis: an apharyngeal-brevifurcate distiome cercaria (A) head and (B) forked tail; an echinostomatid cercaria (C) head, (D) single tail and (E) collar spines; and a xiphidio cercaria $(F)$ head, $(G)$ stylet and $(H)$ single tail 
Three weeks after infection only two spindle-shaped eggs were recovered from the faeces of one of the Mallard ducks. The other duck and the rats remained uninfected. The eggs were identified as those belonging to the genus Trichobilharzia according to the descriptions of avian schistosome eggs (type 3) by Appleton (1982, 1986). This avian cercaria was thus identified as a Trichobilharzia sp. It has been recorded that this type of cercaria is able to penetrate human skin, and in so doing causes cercarial dermatitis, as a result of an allergic response (Picard $\&$ Jousson 2001). Since humans are not suitable hosts the cercariae do not enter the blood stream to mature but perish after penetrating the skin (Cheng 1986).

\section{Echinostome cercaria (Fig. 1C-E and 3A-H)}

The cercaria (Fig. 1C-E and $3 \mathrm{~A}$ ) has a large oval head and a long single tail. The body (Fig. $1 \mathrm{C}$ and 3B) measures 232-292 (262 \pm 21$) \times 52-99(82 \pm$ 15). The most distinctive feature of this cercaria is the horseshoe-shaped collar (Fig. 1E and 3F), consisting of 27 individual spines. They are grouped into four corner spines measuring 10.5-14.9 $(12.1 \pm 1.6)$ $\times 2.9-4.5(3.6 \pm 0.7)$ (Fig. 3E), five lateral spines, 8.5-14.9 $(12.4 \pm 1.9) \times 2.9-4.5(3.9 \pm 0.7)$ and nine dorsal spines arranged into two alternating rows of four oral spines measuring 10.5-11.9 $(11.2 \pm 0.8) x$ 2.9-4.5 (3.6 \pm 0.8$)$ alternating with five aboral spines, $11.9-14.9(13.6 \pm 1.3) \times 2.9-4.5(3.3 \pm 0.6)$ (Fig. $3 F)$.

An oval-shaped and very protrusible oral sucker measures 36-60 $(47 \pm 10) \times 26-67(45 \pm 12)$ at the anterior end of the body. This sucker is surrounded by many long-ciliated receptors (Fig. 3C, E and G) as well as multi-ciliated (cluster) receptors (Fig. 3E and G) consisting of groups with 6 to 12 short cilia. These receptors are situated mostly dorsal and dorso-laterally to the oral sucker (Fig. 3G).

The oral sucker extends into a small pre-pharyngeal sac measuring 16-24 $(19 \pm 2.5) \times 14-25(21 \pm 2.8)$, filled with two large granules of 8.9-14.9 (10.8 \pm 1.9) in diameter (Fig. 1C). It continues into a prepharynx measuring 9-15 $(12 \pm 2) \times 4-7(6 \pm 1)$ that extends into a prominent pharynx, 11-37 $(18 \pm 7) \mathrm{x}$ $10-15(13 \pm 2)$. This leads to an oesophagus measuring 45-82 $(74 \pm 11) \times 7-16(10 \pm 3)$ that bifurcates to form two intestinal caeca measuring 75-135 (106 $\pm 23) \times 9-16(12 \pm 3)$ that terminate at the posterior end of the body. The acetabulum (Fig. 3D) is oval, well-developed and measures 37-63 $(50 \pm 9) \times 40-$ $70(55 \pm 9)$, and is further also situated at a position
$49-127(82+23)$ posterior to the oral sucker and 45-93 (62 \pm 13$)$ from the end of the body.

The excretory bladder is bipartite with the most posterior part larger and oval, measuring 18-45 (32 \pm 9) $\times 15-33(26 \pm 6)$, and preceded by a smaller oval part measuring 7-10 $(9 \pm 1) \times 19-22(21 \pm 1)$ (Fig. $1 \mathrm{C})$. The main excretory ducts on either side of the bladder extend anteriorly towards the pharyngeal region where they fold back posteriorly thus forming anterior and posterior collecting ducts in the midbody. These collecting ducts branch to form capillaries ending in flame cells. Eight flame cells were observed anteriorly and six posterior to the acetabulum. The flame cell formula is as follows: $2[(2+1+$ $2+2)+(1+1+2+1+2)]=28$. A caudal excretory duct was also observed to extend into the anterior part of the tail stem where it branches at a quarter of the tail length into two ducts that open to the outside through two excretory openings (Fig. 1C).

Locomotion is provided by a single muscular tail (Fig. 1D) that is slightly longer than the head, measuring 297-306 (300 \pm 4$) \times 30-59(37 \pm 9)$. It displays various long ciliated papillae arranged bilaterally on the tail stem (Fig. 3H). Finfolds are absent. The tegument of both the body and tail is aspinous and unevenly ridged (Fig. 3F and $\mathrm{H}$ ).

\section{Remarks}

The cercaria is classified as an echinostome cercaria according to the keys provided by Frandsen \& Christensen (1984). Porter (1938) described an echinostomatid cercaria with a collar of 26 spines, Cercaria middelburgensis that was shed by $L$. natalensis collected from a lake in Middleburg, Mpumalanga Province. This cercaria differs from the description of the present cercaria in respect of size, most body structures and the number and arrangement of the collar spines. Fain (1953) described Cercaria bruynoghei and Cercaria decora with 27 spines in the collar. These cercariae differ from the present specimen in the species of the snail host, general sizes of all structures, position of the acetabulum and flame cell formula.

Similarly, Jansen van Rensburg (2001) described a 27-spined echinostomatid cercaria from $L$. natalensis from the Okavango Delta, Botswana. Most body structures are similar to those of the present material but the prepharyngeal sac is absent. In contrast to Porter (1938), King \& Van As (1997) described a 27-spined echinostomatid cercaria that was shed by Bulinus tropicus from the Free State Province. Most of the cercarial features also appear similar to 

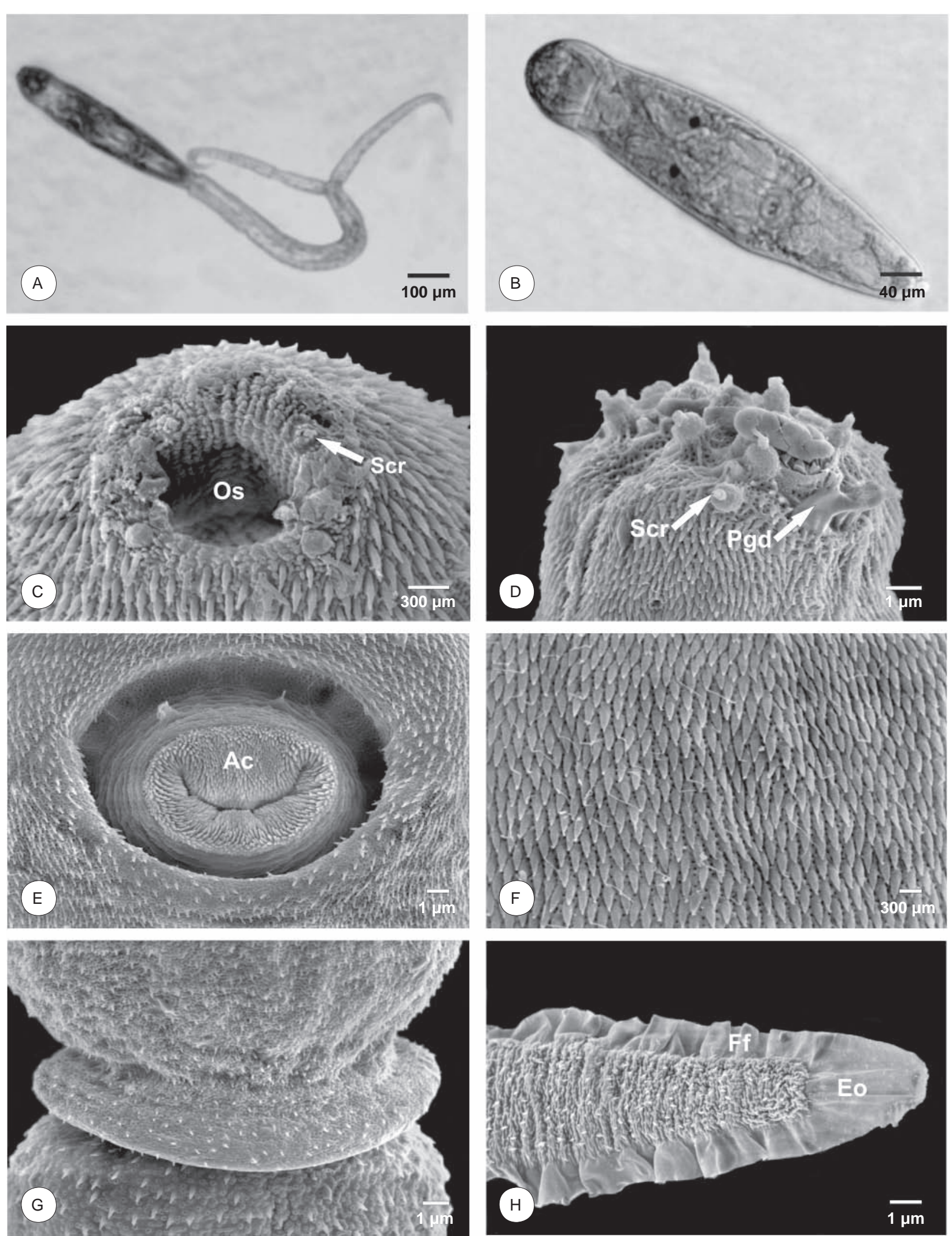

FIG. 2 Apharyngeal-brevifurcate distome cercaria. Light micrographs of (A) whole mount; (B) head of cercaria; (C-H) scanning electron micrographs of cercaria: (C) oral sucker (Os) surrounded by sensory receptors (Scr); (D) sensory receptors (Scr) and penetration gland ducts (Pgd); (E) acetabulum (Ac); (F) tegumental features of body; (G) tegument features of body posteriorly and tail; $(\mathrm{H})$ tail with finfold $(\mathrm{Ff})$ and excretory opening (Eo) 


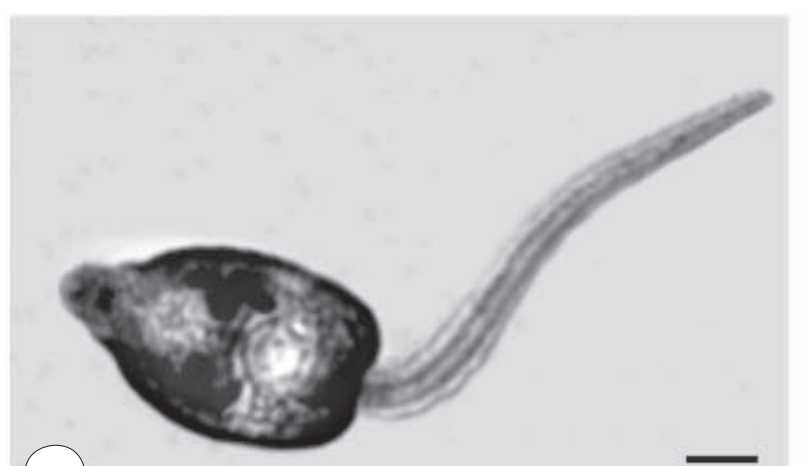

(A)

$\overline{150 \mu \mathrm{m}}$
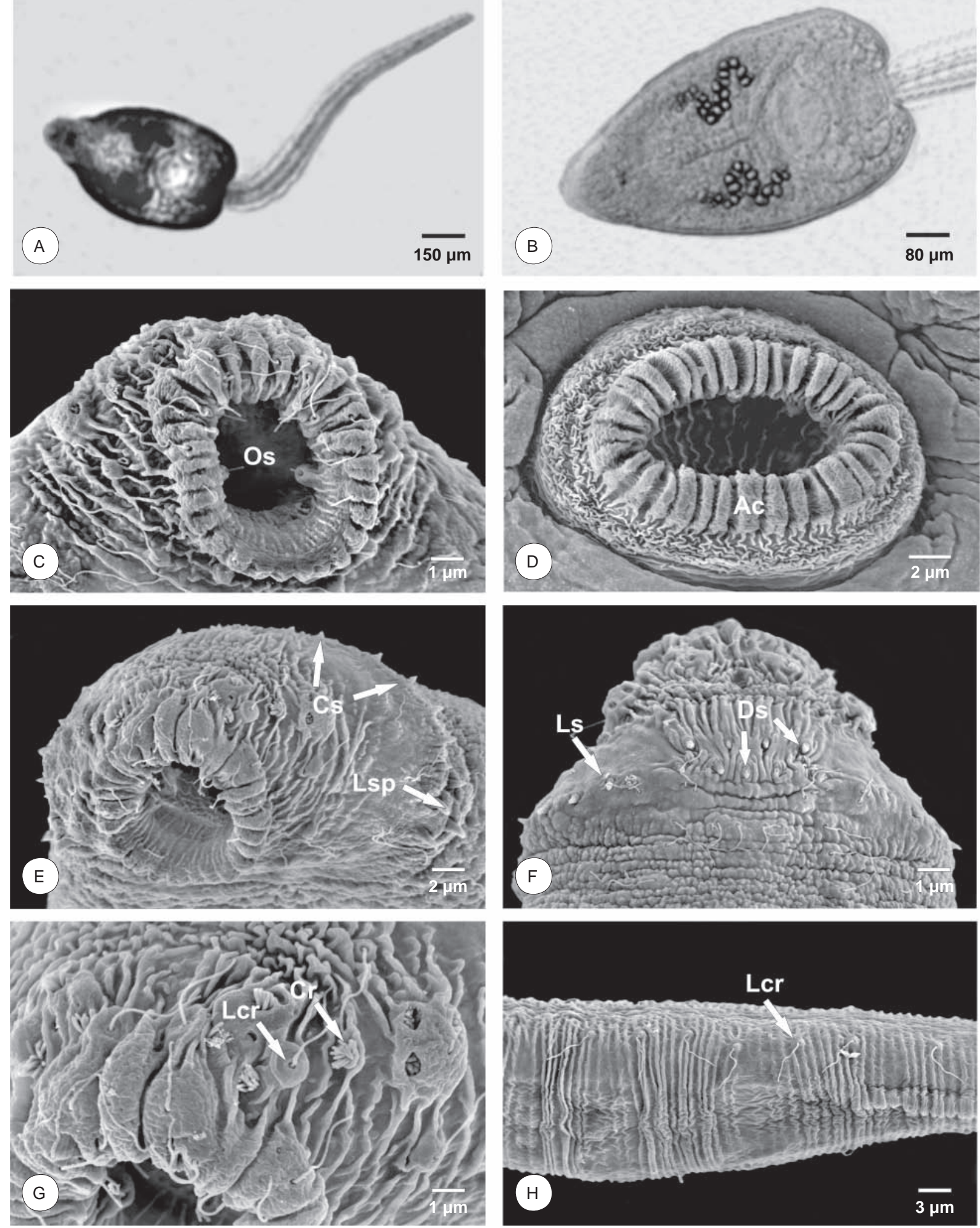

FIG. 3 Echinostomatid cercaria. Light micrographs of $(A)$ whole mount; $(B)$ head of cercaria; $(\mathrm{C}-\mathrm{H})$ scanning electron micrographs of cercaria: (C) oral sucker (Os) surrounded by long ciliated sensory receptors; (D) acetabulum (Ac); (E) sensory receptors along the oral sucker and collar showing corner (Cs) and lateral spines (Lsp); (F) tegumental features and collar spines, lateral spines (Ls) and dorsal spines (Ds); (G) long ciliated (Lcr) sensory and cluster receptors (Cr); (H) tail features with long ciliated receptors (LCr) 
those of this study, with the exception of the content of the prepharyngeal sac and the species of the first intermediate host.

\section{Xiphidiocercaria (Fig. 1F-H and 4A-H)}

The cercaria has a stout oval body and a very short single tail (Fig. 1F, $\mathrm{H}$ and $4 \mathrm{~A}$ ). The body is flattened dorso-ventrally, measuring 172-187 $(176 \pm 5)$ x 43$55(49 \pm 3)$. A well-developed oral sucker (Fig. 4C), measuring $36-43(38 \pm 2) \times 30-37(33 \pm 3)$ is situated at the anterior end of the body. The most characteristic feature of this cercaria, however, is a simple stylet (Fig. 1G and 4B), measuring 18-21 $(19 \pm 1)$ $\times 3-5(3 \pm 1)$, that is situated dorsally to the oral sucker.

The oral sucker leads to a pre-pharynx that is longer than it is wide, measuring 22-27 $(25 \pm 2) \times 7-12$ (8 \pm 2 ). It extends into a well-developed pharynx, 12$18(15 \pm 2) \times 10-15(12 \pm 1)$. The pharynx extends into an oesophagus, measuring 21-31 (23 \pm 3$) \times 7-$ $12(9 \pm 1)$, and bifurcates into two intestinal caeca anterior to the acetabulum and which extend to reach the posterior margin of the acetabulum. The caeca measure 120-123 (121 \pm 1$)$ long x 9-11 (10 \pm 1 ) wide.

The acetabulum is covered by spines of similar length to those on the rest of the body (Fig. 4D). Mid-body, the acetabulum measures 30-36 (32 \pm 2$)$ $x$ 28-37 $(31 \pm 3)$ and is situated 45-48 $(47 \pm 1)$ from the oral sucker. Three pairs of coarsely granulated penetration glands with distinct nuclei were observed at the sides of the acetabulum (Fig. 1F). The first pair of penetration glands measures $9-12(10 \pm 1) \times$ 9-18 $(14 \pm 3)$, the second pair, $10-13(11 \pm 2) \times$ 9-21 (13 \pm 4$)$ and the third pair, 6-12 (9 \pm 2$) \times 9-16$ $(11 \pm 2)$. Penetration gland ducts extend to the oral sucker where they open to the exterior.

The excretory bladder consists of two parts: a larger posterior part, measuring 16-30 (20 \pm 4$) \times 16-37$ $(24 \pm 8)$ and a smaller anterior part, $21-31(23 \pm 3)$ $x$ 21-45 $(28 \pm 8)$. The main excretory ducts extend bilaterally from the anterior bladder to the level of the acetabulum where they fold back posteriorly giving rise to anterior and posterior collecting ducts that eventually form capillaries that terminate in flame cells. Three flame cells were observed anteriorly and two posteriorly. The flame cell formula is $2[(2+1)+$ (2) $]=10$.

Locomotion is provided by a short single tail (Fig. $1 \mathrm{H}$ and $4 \mathrm{H})$ measuring $148-164(152 \pm 6) \times 22-24$ $(23 \pm 1)$, that is aspinous and lacks dorso-ventral fin- folds. The body tegument is evenly granulated and covered by numerous minute backwardly pointing spines (Fig. 4G). Sensory receptors are few, but receptors with long cilia were observed on the sides of the body (Fig. 4F). Short ciliated receptors were also observed on the ventral surface of the body (Fig. $4 \mathrm{E}$ ). Most receptors with short cilia were observed surrounding the oral sucker (Fig. 4C), whereas nonciliated receptors were observed alongside the acetabulum (Fig. 4D).

\section{Remarks}

This cercaria is classified as an Armatae xiphidiocercaria according to the classification keys proposed by Frandsen \& Christensen (1984) and Haseeb (1984). Frandsen \& Christensen (1984) are of the opinion that xiphidio cercariae belonging to the Armatae group develop into intestinal parasites in all groups of vertebrates.

In an earlier work, Porter (1938) described the following nine xiphidio cercariae with three pairs of penetration glands and five to six flame cells on each side of the body: Cercaria elizabethae (Porter, 1938) from Port Elizabeth, Eastern Cape Province; C. grobelaaria from Oudtshoorn, Western Cape Province; C. hartebeestia from the Hartbeestpoort Dam, North West Province; C. nymphaea from Sydenham, KwaZulu Natal Province; $C$. spruitensis from the Hartbeestpoort Dam; C. stonei from Komatipoort, Mpumalanga Province; C. umhlotunzanafrom Clairwood, Kwa-Zulu Natal Province; C. veta from Hoopstad, Free State Province; and C. vuurensis from Middleburg, Mpumalanga Province. Of the nine xiphidio cercariae originally described six were shed by $L$. natalensis, i.e. C. elizabethae, C. hartebeestia, C. nymphaea, C. stonei, C. umhlotunzana and $C$. vuurensis. The cercaria in this study differs from these six cercariae in the morphology of the xiphidio spine, intestinal caecal length, position and arrangement of the penetration glands and morphology of the tail.

Fain (1953) and Vercammen-Grandjean (1960) described five and two xiphidio cercariae with three pairs of penetration glands, respectively. All of these cercariae differ from the present cercarial type by the size and orientation of the penetration glands, flame cell formula, intestinal caeca length and form of the stylet. In contrast, King \& Van As (2001) described three xiphidio cercariae shed by $B$. tropicus in the Free State that all differ in morphology when compared to the present cercaria, e.g. the position and number of penetration glands in the body. 

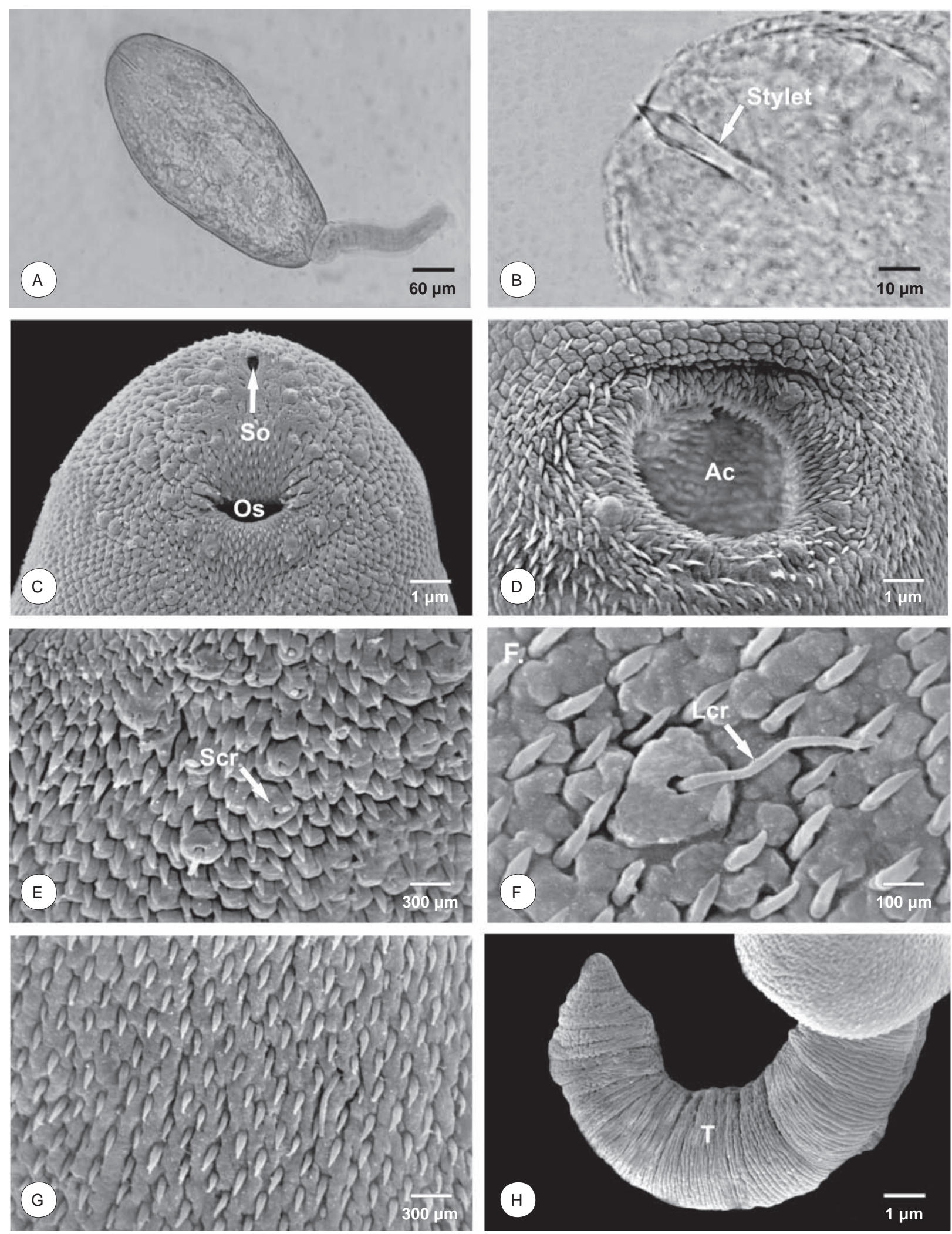

FIG. 4 Xiphidio cercaria. Light micrographs of (A) whole mount; (B) anterior stylet (S); $(C-H)$ scanning electron micrographs of cercaria: (C) oral sucker (Os) and stylet opening (So); (D) acetabulum (Ac); (E) short ciliated receptors (Scr); (F) long ciliated receptors $(\mathrm{Lcr}) ;(\mathrm{G})$ tegumental features of the body; $(\mathrm{H})$ tail $(\mathrm{T})$ features 


\section{DISCUSSION}

The apharyngeal-brevifurcate distome fork-tailed cercaria was found to be an avian schistosome cercaria.

The life cycle studies in the Mallard ducks and Wisstar rats unfortunately produced only two Trichobilharzia eggs in the faeces of one of the Mallard ducks. According to Appleton (2003) 16 adults and 12 cercariae of avian schistosomes have been described from the Afrotropical Region. Nine Trichobilharzia species have been described from birds in central Africa and Madagascar, and Appleton (1982, 1986) recorded five different types of avian schistosome eggs from faecal samples collected at various localities in South Africa. Three Trichobilharzia cercariae were described from L. natalensis in Africa, but since the cercaria in the present study is the smallest and the resulting eggs clearly fall within Trichobilharzia type 3 as was classified by Appleton (1982, 1986 and 2003), this cercaria may well be different from those described earlier. The life cycle therefore needs to be repeated using a larger number of ducks of different species in order to find the adult form and to verify the characteristic eggs.

The echinostomatid cercaria with its collar with 27 spines shed by $L$. natalensis was recovered from most localities. Although the life cycle of this parasite is unknown, $L$. natalensis was found to host echinostomatid metacercarial cysts in the mantle. This snail therefore also serves as second intermediate host for this parasite.

The xiphidiocercaria described in this study was found to be the most abundant single-tailed cercaria in the habitats examined in the proximity of Pretoria. The life cycle of this parasite is also unknown, but other xiphidio stages were also found during this study. Xiphidio metacercariae were found encysted in various second intermediate hosts, i.e. in the gill chambers of freshwater shrimps, in the mantle of $L$. natalensis and occasionally also in the intestine of Barbus paludinosus. The cysts found in freshwater shrimps were bigger in size and the cyst wall was thinner compared to the cysts in $L$. natalensis and B. paludinosus. Although it appears as if freshwater shrimps are the most suitable second intermediate host, surveys have shown that they were not always present, especially during winter months. Studies have also shown that the highest infection with cysts occurs in L. natalensis.

\section{REFERENCES}

APPLETON, C.C. 1982. The eggs of some blood-flukes (Trematoda: Schistosomatidae) from South African birds. South African Journal of Zoology, 17:147-150.

APPLETON, C.C. 1986. Occurrence of avian Schistosomatidae (Trematoda) in South African birds as determined by a faecal survey. South African Journal of Zoology, 21:60-67.

APPLETON, C.C. 1996. Freshwater molluscs of southern Africa. Pietermaritzburg, South Africa: University of Natal Press.

APPLETON, C.C. 2003. The avian schistosomatidae of sub-Saharan Africa with particular reference to Cercaria herini, a cause of dermatitis in people. Proceedings of workshop on African freshwater Malacology, Kampala, Uganda.

BROWN, D.S. 1994. Freshwater snails of Africa and their medical importance, $2^{\text {nd }}$ ed. London: Taylor \& Francis Ltd.

CHENG, T.C. 1986. General parasitology, $2^{\text {nd }}$ ed. Orlando, Florida: Academic Press Inc.

FAIN, A. 1953. Contribution à l'étude des formes larvaires des trematodes au Congo belge et spécialment de la larvae de Schistosoma mansoni. Mémoires Institut Royal Colonial Belge Section de Sciences Naturalles et Médicales, 22:1312.

FRANDSEN, F. \& CHRISTENSEN, N.O. 1984. An introductory guide to the identification of cercariae from African freshwater snails with special reference to cercariae of trematode species of medical and veterinary importance. Acta Tropica, 41:181-202.

HASEEB, M.A. 1984. Studies on larval trematodes infecting freshwater snails in Pakistan. X. Non-virgulate Xiphidio cercariae. Zeitschrift für Parasitenkunde, 70:637-654.

JANSEN VAN RENSBURG, C.J. 2001. Snail borne larval trematodes of the Okavango Delta, Botswana. M.Sc. dissertation, University of the Free State.

KING, P.H. \& VAN AS, J.G. 1997. Description of the adult and larval stages of Tylodelphys xenopi (Trematoda: Diplostomatidae) from Southern Africa. Journal of African Zoology, 83: 287-295.

KING, P.H. \& VAN AS, J.G. 2001. Cercariae shed by Bulinus tropicus (Krauss, 1848) in the Free State, South Africa. Journal of African Zoology, 36:95-105.

PICARD, D. \& JOUSSON, O. 2001. Genetic variability among cercariae of the Schistosomatidae (Trematoda: Digenea) causing swimmer's itch in Europe. Parasite, 8:237-242.

PORTER, A. 1938. The larval Trematoda found in certain South African Mollusca with special reference to schistosomiasis (Bilharziasis). Publications of the South African Institute of Medical Research, 8:1-492.

VAN EEDEN, J.A. 1960. Key to the genera of South African freshwater and estuarine gastropods (Mollusca). Annals of Transvaal Museum, 24:1-17.

VAN EEDEN, J.A., BROWN, D.S. \& OBERHOLZER, G. 1965. The distribution of freshwater molluscs of medical and veterinary importance in southeastern Africa. Annals of Tropical Medicine and Parasitolology, 59:413-424.

VERCAMMEN-GRANDJEAN, P.H. 1960. Les trematodes du Lac Kivi sud. Musée Royal de l'Afrique Centrale, Tervuren. Belgique Annales Novelle serie in $4^{\circ}$ Sciences Zoologiques, 5:1-171. 